\section{Occurrence of Microaerophilic Bacteria in Estuarine Waters of Tokyo Bay} \\ Haruo Sugita,* Naoto Okanoto,* \\ and Yoshiaki Deguchi* \\ (Received March 15, 1990)
}

Short Paper

\begin{abstract}
Microorganisms requiring free oxygen but in low concentration for optimum growth are termed microaerophiles. Since water provides a barrier against the quick replenishment of free oxygen in aquatic environments, microaerophilic bacteria seem to occur abundantly. Although much is known about the ecology and physiology of aerobes/facultative anaerobes, and to a lesser degree, obligate anaerobes, very little has been reported about microaerophiles except for Schlegel and Jannasch, who described that a large number of typically aquatic microorganisms are microaerophilic. Therefore, the present study was undertaken to investigate the distribution of microaerophiles, which cannot grow both aerobically and anaerobically, in estuarine waters of Tokyo Bay.
\end{abstract}

Water and sediment samples were collected with a Kitahara's water sampler and an Ekman-Berge bottom sampler (Rigosha), respectively, at station 1 (2.3-5.2 m depth) of the Ara River mouth, a highly polluted area, during March 1988 to February 1989. Each sample was diluted quantitatively with the seawater diluent,") placed onto three sets of PYBG agar medium ${ }^{2}$ and incubated at $20^{\circ} \mathrm{C}$ for 14 days under either aerobic, microaerobic or anaerobic conditions. The microaerobic condition was established by evacuating the atmosphere of an anaerobic jar and replacing it with $5 \% \mathrm{CO}_{2}-10 \% \mathrm{O}_{2}-85 \% \mathrm{~N}_{2}$ gas mixture. The anaerobic condition was established by the steel wool method.2) After incubation, bacterial colonies were counted, and ca. 40 colonies were isolated at random from each plate, and examined for cellular morphology, spore formation, Gram reaction and abilities to grow aerobically and anaerobically.

As is shown in Fig. 1, viable counts of the microaerophile were: $8.5 \times 10^{1}-1.2 \times 10^{4} \mathrm{CFU} / \mathrm{ml}$ in the $92 \%$ surface water samples; $2.1 \times 10^{1}-4.6 \times 10^{3}$ $\mathrm{CFU} / \mathrm{m} \mathrm{l}$ in the $75 \%$ bottom water samples; and $3.0 \times$ $10^{4}-2.1 \times 10^{5} \mathrm{CFU} / \mathrm{g}$ in the $67 \%$ sediment samples of the Ara River mouth. These counts were generally higher than in water samples but equal to the level of obligate anaerobes in sediment samples whereas they were much less than aerobes/facultative anaerobes in both samples. The reason why the microaerophiles were not detected from $8-33 \%$ samples, may be attributed to either that the microaerophiles were actually absent in those samples, or that they were so few in number, compared with aerobes and anaerobes, that they were not isolatable because the PYBG agar medium used is non-selective. Therefore, a selective

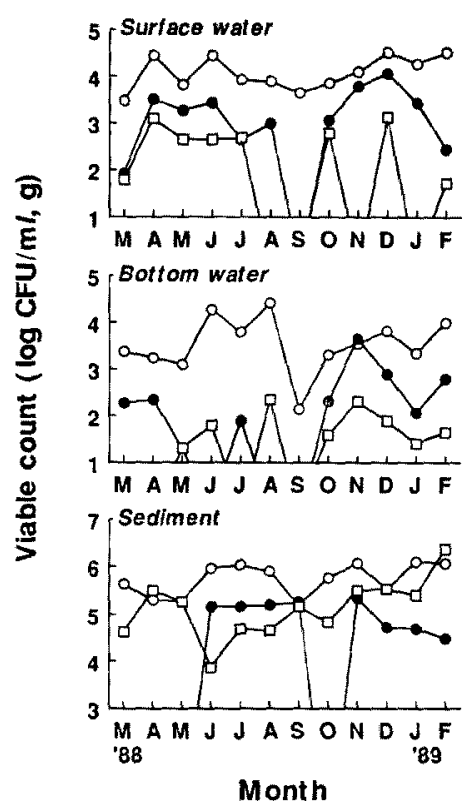

Fig. 1. Monthly changes of aecobes/facultative anaerobes $(0)$, microaerophiles $(\bullet)$ and obligate anaerobes $(\square)$ in the surface and bottom waters and sediments of the Ara River mouth.

medium for obligate microaerophiles is required for a better estimation of them.

On the other hand, a total of 3,360 strains of bacteria were isolated from water and sediment samples, and those were composed of aerobes/facultative anaerobes (3,015 strains), microaerophiles (204) and obligate anaerobes (141). The microaerophiles were further divided into 171 strains of Gram-negative rods and 33 of Gram-positive rods. However, the taxonomic status of those bacteria remains to be elucidated. Nevertheless, the present results strongly suggest that these types of microaerophiles occur widely in estuarine waters and play important roles in the mineralization of coastal ecosystem. Further studies along those lines are in progress.

\section{References}

1) H. G. Schlegel and H.W. Jannasch: in "The Prokaryotes" (ed. by P. Starr et al.), SpringerVerlage, Berlin, 1981, pp. 43-82.

2) H. Sugita, H. Tanaami, T. Kobashi, and $Y$. Deguchi: Nippon Suisan Gakkaishi, 47, 655661 (1981).

* Department of Fisheries, Nihon University, Shimouma, Setagaya, Tokyo 154, Japan (杉田治男, 岡本话

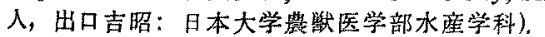

